Fetal Diagnosis and Therapy
Fetal Diagn Ther 2019;45:13-20

DOI: $10.1159 / 000485932$
Received: September 27, 2017

Accepted after revision: November 29, 2017

Published online: January 12, 2018

\title{
Incidence of and Risk Factors for Residual Anastomoses in Twin-Twin Transfusion Syndrome Treated with Laser Surgery: A 15-Year Single-Center Experience
}

\author{
P.J.C. Knijnenburg ${ }^{a} \quad$ F. Slaghekke ${ }^{b} \quad$ L.S.A. Tollenaar ${ }^{b} \quad$ J.M. van Klink ${ }^{a}$ \\ D.P. Zhao ${ }^{a}$ J.M. Middeldorp ${ }^{b}$ M.C. Haak ${ }^{b} \quad$ F.J. Klumper ${ }^{b} \quad$ D. Oepkes ${ }^{b}$ \\ E. Lopriore ${ }^{a}$
}

a Division of Neonatology, Department of Pediatrics, Leiden University Medical Center, Leiden, The Netherlands;

${ }^{b}$ Division of Fetal Medicine, Department of Obstetrics, Leiden University Medical Center, Leiden, The Netherlands

\section{Keywords}

Monochorionic placenta - Twin-twin transfusion syndrome · Fetoscopic laser surgery $\cdot$ Solomon technique $\cdot$ Residual anastomoses $\cdot$ Multifetal gestation

\section{Abstract \\ Objectives: To evaluate the incidence of residual anastomo- ses (RA) after laser therapy for twin-twin transfusion syn- drome (TTS) and investigate risk factors for incomplete laser surgery. Material and Methods: All available TTS placentas treated with laser at our center between 2002 and 2016 were injected with color dye to assess the presence of RA. We eval- uated the incidence of RA over the past 15 years by dividing the cohort into three time periods, and studied the associa- tion with risk factors and neonatal outcome. Results: Overall, RA were detected in $21.0 \%$ (78/371) of placentas. The inci- dence of RA decreased from $38.8 \%(26 / 67)$ in the initial pe- riod to $11.7 \%(16 / 137)$ in the most recent period $(p<0.001)$. On multivariate analysis, several risk factors were indepen- dently associated with the risk of RA, including Solomon la- ser technique (odds ratio [OR] $0.17,95 \% \mathrm{Cl} 0.09-0.33$ ) and estimation of surgical success (OR 19.28, 95\% CI 8.17-45.49).}

Premature delivery and neonatal morbidity occurred more often in TTS cases with RA. Conclusions: The incidence of RA after laser therapy for TTS decreased significantly in the past 15 years and is now below 15\% due to the use of the Solomon technique.

(c) 2018 The Author(s)

Published by S. Karger AG, Basel

\section{Introduction}

Placental vascular anastomoses connecting the circulations of both fetuses are present in almost every monochorionic twin pregnancy and may lead to the development of severe complications such as twin-twin transfusion syndrome (TTS) [1]. Fetoscopic laser coagulation of placental vascular anastomoses is the best treatment for TTS [2]. The aim of fetoscopic laser coagulation is to achieve two separate circulations by coagulating all intertwin vascular anastomoses. Anastomoses may however be missed during fetoscopic surgery, causing severe postoperative complications such as recurrent TTS and twin anemia polycythemia sequence (TAPS) [3-5]. The incidence of these residual anastomoses (RA) varies greatly

E. Lopriore

Department of Pediatrics, Leiden University Medical Center

J6-S, Albinusdreef 2

NL-2333 ZA Leiden (The Netherlands)

E-Mail e.lopriore@lumc.nl 
between the studies from $3.5 \%$ up to $75 \%$ [5-9]. The large variation in the incidence of RA is partly due to methodological limitations related to the study design and often too small sample size. Incomplete laser surgery and RA may be related to various factors, including different laser surgery techniques, experience of the operator (learning curve effect) and location of the placenta (anterior or posterior).

The objective of this study is to evaluate the incidence and consequences of RA after laser therapy for TTS over the years in a large single-center cohort and investigate the role of potential risk factors associated with incomplete laser surgery.

\section{Material and Methods}

\section{Study Design}

All consecutive cases with TTS treated with fetoscopic laser surgery at the Leiden University Medical Center (LUMC) were eligible for this study. The LUMC is the national referral center for fetal surgery in the Netherlands. We included all TTS cases delivered between April 1, 2002, and December 31, 2016, in which the placenta was examined and injected after delivery. The TTS placentas are routinely injected with color dye to assess the presence of RA using a previously reported injection technique [10]. In case of delivery in another center, the placenta was shipped to our hospital for color dye injection. For this study, we excluded placentas with severe placental maceration due to fetal demise of one or more infants. Part of the placental data used in this study has been used in previous reports $[3,5,6,11]$. The study was approved by the Leiden University Medical Centre Medical Ethics Committee.

The following antenatal variables were collected: TTS stage, gestational age at laser, laser technique (selective or Solomon technique), estimation of surgical success according to the operator (recorded directly after laser therapy), location of the placenta (anterior or posterior), number of anastomoses coagulated, and the year laser surgery took place. TTS was defined according to the Eurofoetus criteria [2]. The cut-off was defined as a vertical pocket of amniotic fluid of $\leq 2 \mathrm{~cm}$ for the donor and $\geq 10 \mathrm{~cm}$ for the recipient after 20 weeks' gestational age (or $\geq 8 \mathrm{~cm}$ before 20 weeks' gestational age). Stages of TTS were determined according to the Quintero staging [12]. The presence of post-laser TAPS was defined as Doppler ultrasound examination showing an increased middle cerebral artery peak systolic velocity (MCA-PSV) $>1.5$ multiples of the median (MoM) in one fetus, suggestive for anemia, accompanied by a decreased MCA-PSV $<1.0 \mathrm{MoM}$ in the co-twin, suggestive for polycythemia [4]. Postnatal TAPS was defined as both an intertwin hemoglobin difference of $>8 \mathrm{~g} / \mathrm{dL}$ at birth and at least one of the following: reticulocytosis in the donor with an intertwin reticulocyte count ratio $>1.7$ and/or the presence of only small (diameter $<1 \mathrm{~mm}$ ) anastomoses after placental injection [13]. Estimation of surgical success was defined as whether the surgeon thought all the anastomoses had been coagulated directly after the laser surgery, which was recorded in the patient's records. To study the association between gestational age at laser and RA, we calculated the interquartile range (IQR) of the gestational age at laser. We then divided TTS cases into three categories: early laser group (first quartile), late laser group (third quartile), and the average laser age group (mid-spread, i.e. between upper and lower quartiles).

During the study period, both the selective and Solomon laser techniques were used to treat TTS. The principle of the selective technique is to coagulate all intertwin anastomoses that could be visualized during fetoscopy, whereas the aim of the Solomon technique is to draw a line along the placental vascular equator in order to coagulate even the tiny hardly visible or nonvisible anastomoses. Examples of color-dye-stained placentas treated with the Solomon laser technique and with the selective technique are shown in Figures 1 and 2 . The selective laser technique was routinely used between January 2002 and March 2007. From March 2007 until October 2012 both the selective and Solomon techniques were performed during the open-label randomized controlled Solomon trial [5]. Since October 2012, after completion and evaluation of the Solomon trial results, the Solomon laser technique was routinely used, due to the favorable results. To study the association between study period and RA, we divided the cohort of TTS cases into three groups; pre-Solomon period, the Solomon study period, and the post-Solomon period.

The following postnatal variables were recorded: gestational age at birth, birth weight, neonatal mortality (death of an infant within 28 days after birth), and neonatal morbidity. Neonatal morbidity was defined as the presence of one of the following complications: respiratory distress syndrome needing treatment with surfactant, patent ductus arteriosus requiring medical treatment or surgical closure, necrotizing enterocolitis grade $\geq 2$, severe anemia requiring blood transfusion on the first day after birth, severe polycythemia requiring partial exchange transfusion on the first day after birth, severe cerebral damage which was defined as the presence of one of the following occurrences: cystic periventricular leukomalacia grade $\geq 2$, intraventricular hemorrhage grade $\geq 3$, ventricular dilatation greater than the 97 th percentile, porencephalic or parenchymal cysts, arterial or venous infarction, or other severe cerebral lesions associated with adverse neurological outcome.

The primary outcome was the incidence of RA assessed with color dye injection of the placenta. As secondary outcomes, we studied the association between RA and potential risk factors and the association between RA and neonatal morbidity and mortality.

\section{Statistical Analysis}

Group differences were compared using an independent samples $t$ test. Antenatal risk factors for RA were compared using univariable logistic regression. A $p$ value $<0.05$ was considered to indicate statistical significance. The following potential predictors of the presence of RA were studied in a univariable logistic regression model: laser technique, laser period, gestational age at laser surgery, Quintero stage, location of the placenta, and the estimation of surgical success. Predictors of RA that were significant $(p<0.05)$ in the univariable analysis were included in a multivariable logistic regression model to measure the independent effects. The results of the logistic models were expressed as odds ratio (OR) and 95\% confidence interval (CI). Data on neonatal outcome were compared using a generalized estimating equation (GEE) to account for the fact that findings between co-twins are not independent. Likewise, neonatal outcome variables that appeared significant in the univariable GEE were included in a multivariable GEE. Results 


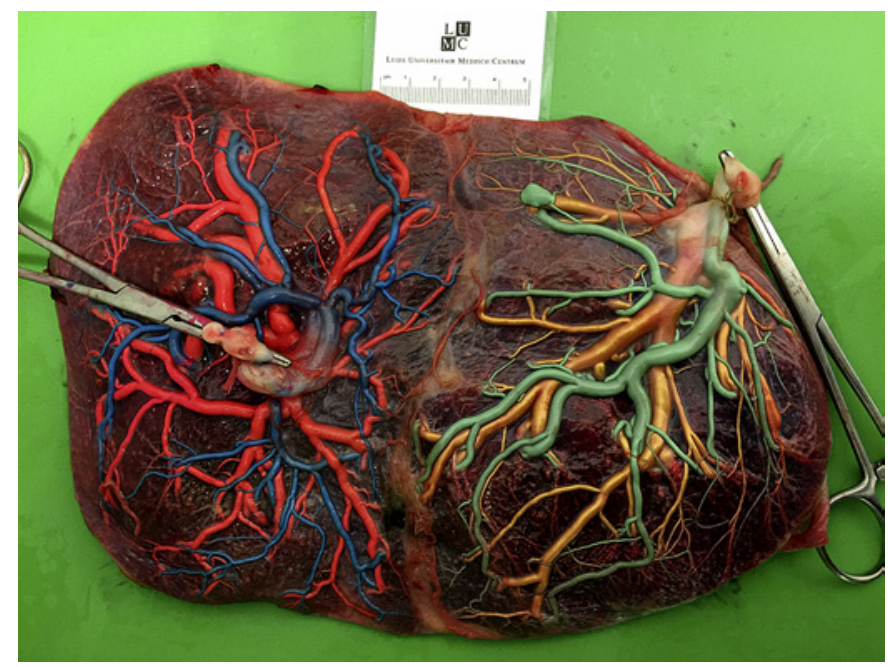

Fig. 1. TTS placenta treated using the Solomon laser technique. Blue and green dye was used to stain the arteries, pink and yellow were used to stain the veins. No residual anastomoses were detected.

were defined in percentages, mean and standard deviation, or median and IQR, depending on the distribution, and ORs with a $95 \%$ CI. All statistical data were analyzed using SPSS version 23.0 (IBM, Chicago, IL, USA).

\section{Results}

During the 15-year study period, 645 monochorionic twin pregnancies were treated with fetoscopic laser surgery for TTS at our center. A total of $436(67.6 \%)$ pregnancies resulted in 2 liveborn infants. We excluded 99 $(22.7 \%)$ liveborn infants due to fixation of the placenta in formalin $(n=5)$, placental damage $(n=11)$, or loss of the placenta $(n=83)$. A total of $34(16.3 \%)$ placentas of cases with one or more fetal demises could be injected. The derivation of our population is presented in Figure 3. Mean gestational age at birth in the group of lost placentas was significantly higher compared to the group included in the study, 33.3 versus $31.9(p=0.01)$. Of the 371 placentas included in the study, 249 (72.5\%) were delivered in our center and 122 (27.5\%) elsewhere and subsequently shipped to our center. Most placentas that were lost were from twins delivered elsewhere $(91.6 \%, 76 / 83)$ and probably not shipped over after birth. The baseline characteristics of our population are presented in Table 1. Post-laser TAPS was found in 53 of 645 cases (8.2\%). Recurrent TTS was found in 11 pregnancies (1.7\%). Of

Incidence of Residual Anastomoses after Laser for TTS

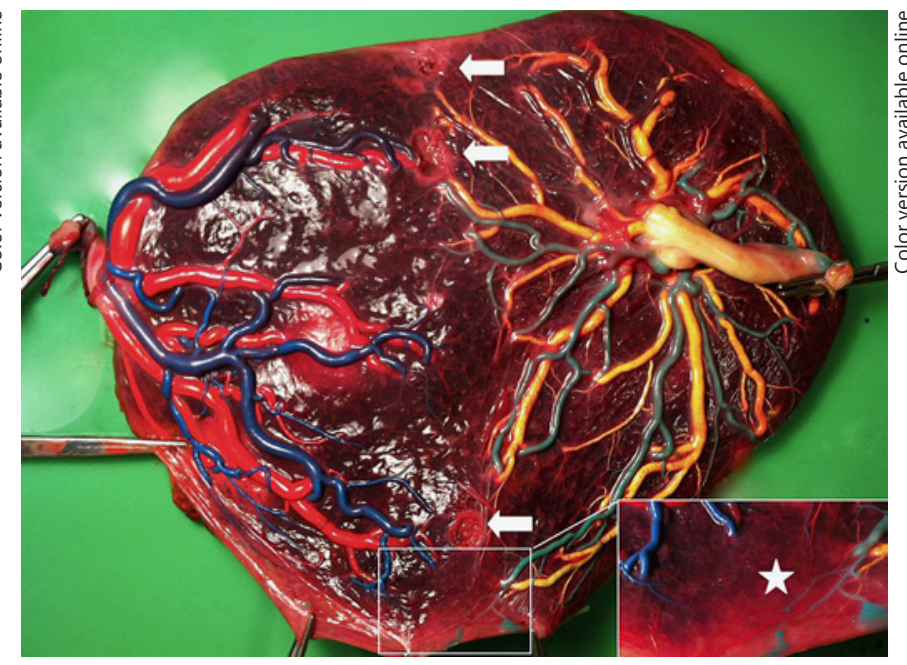

Fig. 2. TTS placenta treated using the selective laser technique. The white arrows indicate the laser spots. The white star indicates a venoarterial anastomosis. Picture previously published in Fetal Diagnosis and Therapy [15].

Table 1. Baseline characteristics of 371 TTTS pregnancies treated with laser

$\begin{array}{lc}\text { Quintero stage } & \\ \text { I } & 47(12.7) \\ \text { II } & 124(33.4) \\ \text { III } & 183(49.3) \\ \text { IV } & 17(4.6) \\ \text { Gestational age at laser, weeks } & 20.0(18.0-22.0) \\ \text { Anterior placenta } & 156(42.0) \\ \text { Anastomoses detected during fetoscopy } & 6.0(4.0-8.0) \\ \text { Caesarean section } & 138(37.2) \\ \text { Born at our center } & 269(72.5) \\ \text { Female gender } & 185(49.9)\end{array}$

Data are presented as $n(\%)$ or median (IQR).

the placentas with RA, $47.4 \%$ developed post-laser TAPS or recurrent TTS. Reintervention with laser surgery was performed in 12 pregnancies, and 17 twins were managed with intrauterine blood transfusions. In 3 of the 12 cases with a laser reintervention, laser surgery was unsuccessful, and RA were found on the postpartum examination of the placenta. These placentas were therefore analyzed in the RA group. RA were not found in only 2 placentas, whereas 7 placentas could not be injected.

Overall, RA were detected in $68(21.0 \%)$ placentas. We found a clear decline in the incidence of RA during 


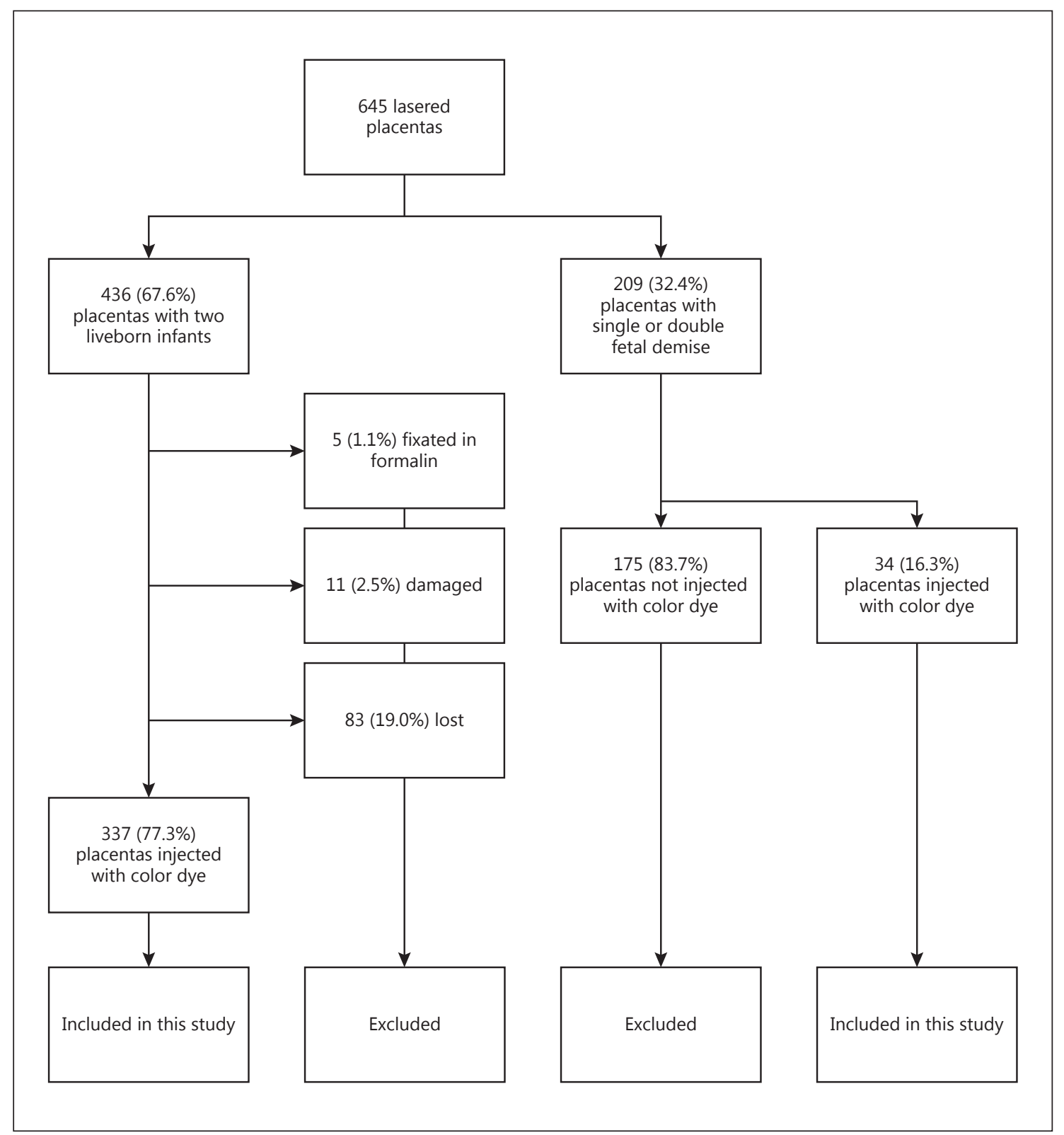

Fig. 3. Derivation of the study population.

the years, from $38.8 \%(26 / 67)$ in the first period (preSolomon period: January 2002 to May 2007) to $11.7 \%$ $(16 / 137)$ in the most recent period (post-Solomon period: July 2012 to December 2016) (OR 4.80, 95\% CI 2.89-7.96, $p<0.001$ ) (Fig. 4). The selective laser technique was associated with an increased risk of RA compared to the Solomon laser technique, 31.6\% (50/158) versus $13.1 \%(28 / 213)$ (OR $0.33,95 \%$ CI $0.19-0.55, p<$ $0.001)$.
We found a clear association between the estimation of surgical success and the presence of RA. RA were found in $63.4 \%$ (26/41) of cases when the surgeon thought the laser therapy was incomplete, compared to $15.8 \%$ $(52 / 330)$ when laser surgery was thought to be complete (OR 11.33, 95\% CI 5.96-21.56, $p<0.001$ ). When the Solomon technique was performed, RA were still found in $7.6 \%(14 / 184)$ of cases considered complete according to the surgeon. 


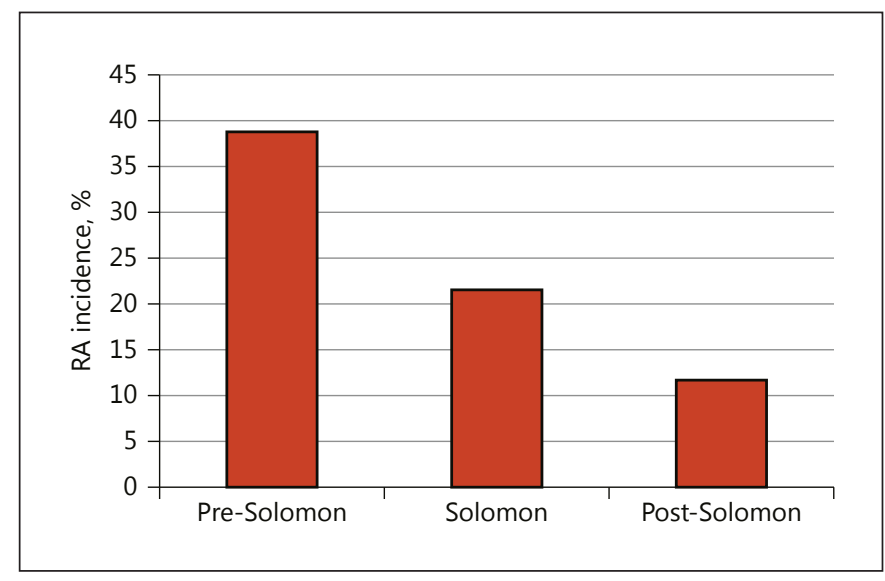

Fig. 4. Incidence of residual anastomoses (RA) in periods of 3 years.

Laser therapy was performed at a median age of 20 weeks (IQR 18-22 weeks). RA were detected slightly more frequently in the early laser group $(<18$ weeks) (OR $1.48,95 \%$ CI $0.78-2.81$ ) and significantly more frequently in the late laser group (>22 weeks) (OR 2.76, 95\% CI $1.48-4.81)$ compared to the average age at laser group, $21.1 \%(19 / 90)$ and $32.6 \%(30 / 92)$ versus $15.3 \%(29 / 189)$ $(p=0.235$ and $p=0.001)$, respectively.

TTS cases with stage 1 had the lowest rate of RA (12.8\%, $6 / 47)$, whereas the highest rate of RA was detected in cases with TTS stage $4(29.4 \%, 5 / 17)$ (OR 2.85, 95\% CI 1.10 $7.40, p=0.032$ )

The incidence of RA was higher in anterior placentas $(24.4 \%, 38 / 156)$ than in posterior placentas $(18.6 \%$, $40 / 215$ ), but the difference was not significant (OR 1.41, 95\% CI 0.85-2.33, $p=0.18$ ).

Multivariable logistic regression was performed using all variables with a significant association with $\mathrm{RA}$ in the univariable logistic regression. An exception was made for the time period in which laser therapy took place, since this variable was highly correlated with the type of laser technique (selective laser technique being performed routinely in the early periods and the Solomon technique in the latter time periods). Therefore, only laser technique (selective vs. Solomon) was analyzed in the multivariable analysis. We found that four risk factors were independently associated with increased risk of RA including selective laser technique, opinion of the surgeon directly after surgery, early and late gestational age at laser, and Quintero stage II (Table 2).

The presence of RA was associated with an increased risk of premature delivery, low birth weight, respiratory

Incidence of Residual Anastomoses after Laser for TTS distress syndrome, patent ductus arteriosus, anemia at birth, polycythemia at birth, and neonatal mortality (Table 3). Gestational age at birth and birth weight were highly associated with all other variables. To correct for intervariable associations and correlation with gestational age at birth and birth weight, we performed a multivariable GEE on all variables which showed a significant correlation with RA in the univariable GEE. Presence of RA was independently associated with an increased risk of patent ductus arteriosus and anemia and polycythemia at birth.

\section{Discussion}

Our study shows a strong decrease in the incidence of RA after fetoscopic laser coagulation in our center over the past 15 years, suggesting an improvement in the completeness of laser surgery. The incidence of RA dropped from $38.8 \%$ in the first period (January 2002 to March 2007 ) to $11.7 \%$ in the most recent period (October 2012 to December 2016), once the Solomon laser technique was routinely used in all cases. Our findings confirm the significant impact of the Solomon technique on the reduction of RA and completeness of laser surgery $[3,5]$. Our study also confirms that the estimation of surgical success, directly after laser, is highly predictive of the presence of RA. When surgeons thought that surgery was incomplete, RA were then detected in $63.4 \%$ of cases. However, in approximately $15 \%$ of the procedures considered complete by the surgeon, RA could still be found. Close monitoring is therefore needed for all post-laser therapy pregnancies, even if the surgeon thinks that the operation was successful. We advise to perform at least biweekly Doppler ultrasound examinations after laser surgery, to screen for signs of anemia and polycythemia (TAPS) or recurrent TTS.

A novel finding in this study is the increased risk of RA in TTS treated with laser at an early or at a late gestational age, i.e. before 18 weeks of gestation and after 22 weeks of gestation at the time of surgery. Hypothetically, anastomoses may be missed more frequently during laser surgery early in pregnancy as these anastomoses are then smaller and may be harder to visualize during fetoscopy. In contrast, anastomoses may also be missed more frequently late in pregnancy because of the larger size of the fetuses which may block the view on the vascular equator. Another explanation is that the size of the placenta may then be too large to oversee the whole vascular equator, especially the placenta margin, and the length and angle of the scope might not be sufficient enough. Increased 
Table 2. Antenatal risk for residual anastomoses

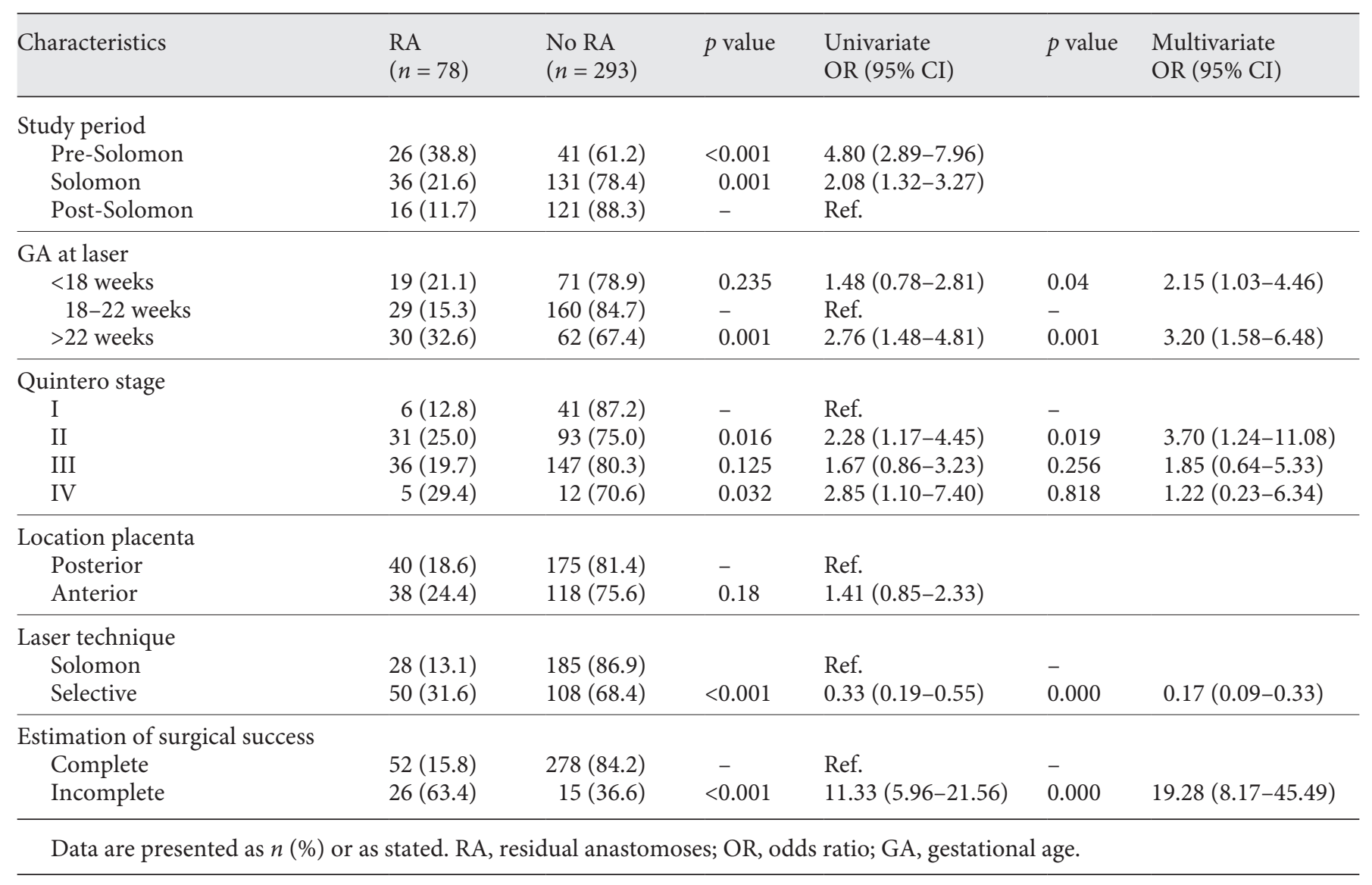

Table 3. Neonatal outcome in the group with 2 live born infants with and without residual anastomoses

\begin{tabular}{|c|c|c|c|c|c|c|}
\hline GA at birth, weeks & $31.9(28.5-34.1)$ & $33.3(30.4-35.7)$ & 0.005 & $3.75(1.51-9.36)$ & & \\
\hline Birth weight, $g$ & $1,518(1,101-1,974)$ & $1,790(1,308-2,225)$ & 0.002 & $10.11(2.33-43.95)$ & & \\
\hline Respiratory distress syndrome & $39(28.7)$ & $89(16.5)$ & 0.038 & $1.83(1.04-3.22)$ & 0.386 & $0.71(0.33-1.53)$ \\
\hline Necrotizing enterocolitis & $1(0.7)$ & $14(2.6)$ & 0.133 & $0.21(0.03-1.62)$ & & \\
\hline Severe cerebral injury ${ }^{\mathrm{a}}$ & $12(8.8)$ & $29(5.4)$ & 0.337 & $1.44(0.69-3.00)$ & & \\
\hline Anemia at birth & $29(21.3)$ & $10(1.9)$ & $<0.001$ & $13.75(6.40-29.55)$ & 0.000 & $15.56(6.98-34.70)$ \\
\hline Polycythemia at birth & $20(14.7)$ & $5(0.9)$ & $<0.001$ & $17.65(6.65-46.84)$ & 0.000 & $24.61(8.90-68.08)$ \\
\hline
\end{tabular}

Data are presented as $n$ (\%) or median (IQR). RA, residual anastomoses. ${ }^{\text {a }}$ Defined as PVL $\geq 2, \mathrm{IVH} \geq 3$, ventricular dilatation, arterial or venous infarct or other severe cerebral injury. 
awareness of these factors may be required to avoid missing anastomoses when performing laser surgery at an early or late gestational age. Another novel and quite remarkable finding in this study is the risk Quintero stages II and IV confer for RA compared to Quintero stage I. The cause of this association is not clear. However, this study might be underpowered to compare Quintero stages since the groups with Quintero stages I and IV were relatively small, and the study was not designed to evaluate possible causes for the associations.

Our study also confirms the association between RA and adverse neonatal outcome, in particular lower gestational age at birth and birth weight, neonatal mortality, and various neonatal morbidities including respiratory distress syndrome, patent ductus arteriosus, and hematological complications (anemia or polycythemia at birth). As previously shown, the presence of RA is associated with the development of post-laser TAPS and recurrent TTS due to the persistence of intertwin fetal transfusion [3].

The strength of this study is the large time span and number of injected placentas that were used and the systematic and accurate method of injection with colored dye. However, care should be taken when interpreting our results due to the retrospective nature of our study and the loss to follow-up. Since the gestational age at birth in the group with placentas which were lost was higher, a selection bias towards the inclusion of more severe cases (with lower gestational age at birth) might have occurred. This could have led to an overestimation of the incidence of RA. Another inevitable limitation of this study is the impossibility to inject placentas with fetal demise. Hypo- thetically, fetal demise may have occurred more frequently in cases of incomplete laser surgery (and thus RA), and this may in turn have led to an underestimation of the incidence of RA.

Lastly, this study did not evaluate the effect of the learning curve and growing expertise of the surgeon. To investigate this important factor, a cumulative sum analysis should be performed for each operator. This effect has already been shown in a previous study in our center [14].

In conclusion, the incidence of RA (and therefore post-laser TAPS and recurrent TTS) after fetoscopic laser coagulation for TTS has rapidly decreased over the years, due to the introduction of the Solomon laser technique and growing laser expertise (learning curve effect). Nevertheless, RA are still not infrequent, particularly in cases treated at an early or late gestational age. Further reduction of RA is important, given the association with adverse neonatal outcome.

\section{Disclosure Statement}

All authors report no conflict of interest.

\section{Funding Sources}

D.P. Zhao is funded by the Key Disciplines Group Construction Project of Pudong Health Bureau of Shanghai (PWZxq2014-02).

\section{References}

1 Lewi L, Jani J, Blickstein I, Huber A, Gucciardo L, Van Mieghem T, Done E, Boes AS, Hecher K, Gratacos E, Lewi P, Deprest J: The outcome of monochorionic diamniotic twin gestations in the era of invasive fetal therapy: a prospective cohort study. Am J Obstet Gynecol 2008;199:514.e511-e518.

-2 Senat MV, Deprest J, Boulvain M, Paupe A, Winer N, Ville Y: Endoscopic laser surgery versus serial amnioreduction for severe twinto-twin transfusion syndrome. N Engl J Med 2004;351:136-144

-3 Slaghekke F, Lewi L, Middeldorp JM, Weingertner AS, Klumper FJ, Dekoninck P, Devlieger R, Lanna MM, Deprest J, Favre R, Oepkes D, Lopriore E: Residual anastomoses in twin-twin transfusion syndrome after laser: the Solomon randomized trial. Am J Obstet Gynecol 2014;211:285.e281-e287.
4 Robyr R, Lewi L, Salomon LJ, Yamamoto M, Bernard JP, Deprest J, Ville Y: Prevalence and management of late fetal complications following successful selective laser coagulation of chorionic plate anastomoses in twin-totwin transfusion syndrome. Am J Obstet Gynecol 2006; 194:796-803.

5 Slaghekke F, Lopriore E, Lewi L, Middeldorp JM, van Zwet EW, Weingertner AS, Klumper FJ, DeKoninck P, Devlieger R, Kilby MD, Rustico MA, Deprest J, Favre R, Oepkes D: Fetoscopic laser coagulation of the vascular equator versus selective coagulation for twinto-twin transfusion syndrome: an open-label randomised controlled trial. Lancet (London) 2014;383:2144-2151.
6 Lopriore E, Slaghekke F, Middeldorp JM, Klumper FJ, Oepkes D, Vandenbussche FP: Residual anastomoses in twin-to-twin transfusion syndrome treated with selective fetoscopic laser surgery: localization, size, and consequences. Am J Obstet Gynecol 2009; 201:4.

7 Quintero RA, Chmait RH, Bornick PW, Kontopoulos EV: Trocar-assisted selective laser photocoagulation of communicating vessels: a technique for the laser treatment of patients with twin-twin transfusion syndrome with inaccessible anterior placentas. J Matern Fetal Neonatal Med 2010;23:330-334.

8 De Paepe ME, Friedman RM, Poch M, Hansen K, Carr SR, Luks FI: Placental findings after laser ablation of communicating vessels in twin-to-twin transfusion syndrome. Pediatr Dev Pathol 2004;7:159-165.
Incidence of Residual Anastomoses after Laser for TTS 
9 Lewi L, Jani J, Cannie M, Robyr R, Ville Y, Hecher K, Gratacos E, Vandecruys H, Vandecaveye V, Dymarkowski S, Deprest J: Intertwin anastomoses in monochorionic placentas after fetoscopic laser coagulation for twinto-twin transfusion syndrome: is there more than meets the eye? Am J Obstet Gynecol 2006;194:790-795.

10 Lopriore E, Slaghekke F, Middeldorp JM, Klumper FJ, van Lith JM, Walther FJ, Oepkes D: Accurate and simple evaluation of vascular anastomoses in monochorionic placenta using colored dye. J Vis Exp 2011;e3208.
1 Lopriore E, Middeldorp JM, Oepkes D, Klumper FJ, Walther FJ, Vandenbussche FP: Residual anastomoses after fetoscopic laser surgery in twin-to-twin transfusion syndrome: frequency, associated risks and outcome. Placenta 2007;28:204-208.

12 Quintero RA, Morales WJ, Allen MH, Bornick PW, Johnson PK, Kruger M: Staging of twin-twin transfusion syndrome. J Perinatol 1999; 19:550-555.

13 Slaghekke F, Kist WJ, Oepkes D, Pasman SA, Middeldorp JM, Klumper FJ, Walther FJ, Vandenbussche FP, Lopriore E: Twin anemia-polycythemia sequence: diagnostic criteria, classification, perinatal management and outcome. Fetal Diagn Ther 2010;27:181-190.
14 Peeters SH, Van Zwet EW, Oepkes D, Lopriore E, Klumper FJ, Middeldorp JM: Learning curve for fetoscopic laser surgery using cumulative sum analysis. Acta Obstet Gynecol Scand 2014;93:705-711.

15 Genova L, Slaghekke F, Klumper FJ, Middeldorp JM, Steggerda SJ, Oepkes D, Lopriore E: Management of twin anemia-polycythemia sequence using intrauterine blood transfusion for the donor and partial exchange transfusion for the recipient. Fetal Diagn Ther 2013;34:121-126. 